\title{
Economic Advantages of Telehealth and Virtual Health Practitioners: Return on Investment Analysis
}

Centaine L Snoswell ${ }^{1}$, PhD, MPH, BPharm; John B North², MBBS, FRACS, FAOrthA; Liam J Caffery ${ }^{1}$, PhD, BInfoTech, DipAppSc

${ }^{1}$ Centre for Online Health, The University of Queensland, Brisbane, Australia

${ }^{2}$ Department of Orthopaedics, The Princess Alexandra Hospital, Brisbane, Australia

\section{Corresponding Author:}

Centaine L Snoswell, PhD, MPH, BPharm

Centre for Online Health

The University of Queensland

Building 33, Princess Alexandra Hospital

Brisbane, 4102

Australia

Phone: 61731765314

Email: c.snoswell@uq.edu.au

\section{Abstract}

Background: Telehealth is a disruptive modality that challenges the traditional model of having a clinician or patient physically present for an appointment. The benefit is that it offers the opportunity to redesign the way services are offered. For instance, a virtual health practitioner can provide videoconference consultations while being located anywhere in the world that has internet. A virtual health practitioner also obviates the issues of attracting a specialist medical workforce to rural areas, and allows the rural health service to control the specialist services that they offer.

Objective: The aim of this research was to evaluate the economic effects of 3 different models of care on rural and metropolitan hospital sites. The models of care examined were patient travel, telehealth using videoconferencing, and employment of a virtual health practitioner by a rural site.

Methods: Using retrospective activity data for 3 years, a return on investment (ROI) analysis was undertaken from the perspective of a rural site and metropolitan partner site using a telehealth orthopedic fracture clinic as an example. Further analysis was conducted to calculate the number of patients that would be required to attend the clinic in each model of care for the sites to break even.

Results: The only service model that resulted in a positive ROI for the rural site over the 3-year period was the virtual health practitioner model. The breakeven analysis demonstrated that the rural site required the lowest number of patients to recoup costs in the virtual health practitioner model of care. The rural site was unable to recoup its costs within the travel model due to the lack of opportunity for reimbursement for services and the requirement to cover the cost of travel for patients.

Conclusions: Our model demonstrated that rural health care providers can increase their ROI by employing a virtual health practitioner.

(JMIR Perioper Med 2020;3(1):e15688) doi: $\underline{10.2196 / 15688}$

\section{KEYWORDS}

clinical services; e-health; health economics; health funding and financing; rural and remote health; workforce

\section{Introduction}

Telehealth is a disruptive modality that challenges the traditional model which requires the clinician and patient to be physically present for an appointment. It is widely accepted that telehealth increases patient access, increases productivity potential for clinicians, and potentially reduces costs for service providers
[1-4]. Although it is disruptive, telehealth often seeks to emulate traditional service models. For example, when a rural and remote service cannot provide specialist care, the patient is traditionally transported to a metropolitan partner facility; with telehealth, patients can access specialist care from the same metropolitan partner facility without having to travel. 
Telehealth represents a valuable opportunity to redesign health service models in Australia. In one potential redesign, rural and remote health services can employ virtual health practitioners. A virtual health practitioner is an employee who works remotely but is otherwise considered to be a regular employee of the organization [5]. The standard telehealth model often functions by connecting two sites: one site employs a specialist health practitioner, and the other site requires a consultation from that specialist. The virtual health practitioner model enables the site that requires a specialist health practitioner to employ that staff resource directly. Use of telehealth by virtual health practitioners to provide specialist services has been previously reported; however, the economic advantages of telehealth for these sites have not been investigated [6].

Assuming regulatory requirements are met, a virtual health practitioner can be located at any site that has internet access, including metropolitan and rural areas. A virtual health practitioner can reduce patient travel and associated costs, which is of particular interest when travel is subsidized by the health care provider. Furthermore, employing virtual health practitioners can obviate the difficulty of attracting medical specialists to rural areas and can allow the health service employing the specialists to control their specialist workforce and the services they offer [7].

Using an orthopedic fracture clinic as an example, this research explores the economic impacts of 3 different models of care: telehealth using videoconferencing (rural site to metropolitan partner), patient travel (rural site to metropolitan partner), and employing a virtual health practitioner at a rural site. The aim of this study was to evaluate the costs and ROI for rural and metropolitan sites for each of the 3 models of care.

\section{Methods}

An analysis of return on investment (ROI) was undertaken from the perspectives of a rural site and a metropolitan partner site. Ethics approval was obtained from the Metro South Human Research Ethics Committee, HREC/17/QPAH/438.

\section{Setting}

The state health department in the Australian state of Queensland is divided into 16 hospital and health services (HHSs). Some of these HHSs are located in metropolitan areas and provide a wide range of specialist services. In addition, some HHSs are located in rural and remote areas, where recruitment and retention of health care professionals can be difficult [2]. Patients are transferred to a metropolitan HHS when the rural HHS cannot provide specialty care.

This example is based on a consultant-led fracture clinic using real-time video consultations between a tertiary facility, Princess Alexandra Hospital, which is located in metropolitan Brisbane (the capital city of Queensland), and Mount Isa Hospital, which is located in remote Queensland. A pilot study examining the cost-effectiveness of this clinic demonstrated substantial cost savings for the remote HHS [8,9]. Prior to the introduction of telehealth, fracture clinic patients were required to drive or be transported to Townsville Hospital (approximately 900 kilometers from Mount Isa Hospital).

Mount Isa Hospital is part of the North West HHS, which spent approximately $\mathrm{A} \$ 16.6$ million on patient transport in the 2016-2017 financial year, accounting for $9.4 \%$ of their spending [10]. Since only a small proportion of patients $(17 \%$ in the 2016-2017 financial year) received a subsidy for their travel, these costs do not represent the full societal burden of patient travel for health care services. The Queensland Health Travel Subsidy Scheme eligibility criteria now state that individuals are only eligible for subsidized travel if they are "unable to use telehealth to access the required eligible specialist medical service" [11].

\section{Data Collection}

Retrospective data for the Metro South HHS telehealth orthopedic fracture clinic for the financial years of 2014-2015, 2015-2016, and 2016-2017 were accessed from the hospital data repository (Table 1).

Table 1. Telehealth activity reported for the orthopedic clinic during the 2014-2015, 2015-2016, and 2016-2017 financial years.

\begin{tabular}{llllllll}
\hline Financial year & Total patients, $n$ & Clinics, $\mathrm{n}$ & $\begin{array}{l}\text { New patient } \\
\text { bookings, } \mathrm{n}(\%)\end{array}$ & $\begin{array}{l}\text { Review patient } \\
\text { bookings, } \mathrm{n}(\%)\end{array}$ & $\begin{array}{l}\text { Adult patient } \\
\text { bookings, n (\%) }\end{array}$ & $\begin{array}{l}\text { Pediatric patient } \\
\text { bookings, } \mathrm{n}(\%)\end{array}$ & $\begin{array}{l}\text { Failed to attend, } \\
\mathrm{n}(\%)\end{array}$ \\
\hline $2014-2015$ & 321 & 31 & $175(55)$ & $146(45)$ & $279(87)$ & $42(13)$ & $53(17)$ \\
$2015-2016$ & 1235 & 82 & $686(56)$ & $549(44)$ & $776(63)$ & $459(37)$ & $321(26)$ \\
$2016-2017$ & 1136 & 82 & $612(54)$ & $524(46)$ & $915(81)$ & $221(19)$ & $318(28)$ \\
\hline
\end{tabular}

Clinic attendance information was used to calculate the costs and ROIs of three different care models: a videoconference telehealth model (the patient at Mount Isa Hospital contacts a specialist at Princess Alexandra Hospital), a travel model (the patient travels to Townsville Hospital for a telehealth consultation), and a virtual health practitioner model (the patient at Mount Isa Hospital contacts a remote virtual practitioner employed by Mount Isa Hospital). The involved hospitals, descriptions of the service models, costs, and income for each care model are outlined in Table 2. 
Table 2. Details of the three examined models of care.

\begin{tabular}{llll}
\hline Characteristic & Telehealth clinic & Patient travel & Virtual health practitioner \\
\hline Involved hospitals & $\begin{array}{l}\text { Mount Isa Hospital (small remote hospi- } \\
\text { tal) and Princess Alexandra Hospital } \\
\text { (tertiary metropolitan hospital) }\end{array}$ & $\begin{array}{l}\text { Townsville Hospital (large regional } \\
\text { hospital) }\end{array}$ & $\begin{array}{l}\text { Mount Isa Hospital (small remote hos- } \\
\text { pital) }\end{array}$
\end{tabular}

Service model description A videoconference is held between the patient at Mount Isa Hospital and a specialist at Princess Alexandra Hospital. The specialist is employed by Princess Alexandra Hospital.

Cost allocation

Income

\section{Cost Analysis}

In ROI analysis, the cost-to-benefit ratio is calculated by dividing the total net benefit by the total cost, allowing outcomes to be expressed in terms of percentage of gain relative to cost [12]. To calculate the ROI in this study, the total cost was based on the costs of human resources and patient-subsidized travel, and the net benefit was determined from the activity-based funding each site received for each nonadmitted outpatient event.

All human resource costs were calculated using published wages for the 2016-2017 financial year [13], and on-costs were added according to the workplace agreements (23\% extra for medical officers and $29 \%$ extra for all other staff). To calculate wages for previous years, a discount rate of $2.5 \%$ per year was used in accordance with Queensland Health workplace agreements. Income for each site was calculated by assuming that $100 \%$ of patients who attended appointments received the applicable activity-based funding. Activity-based funding rebates were based on the appropriate National Weighted Activity Unit (NWAU) code for the respective years, taking into account whether the event was a new or review case [14]. NWAU 20.29 was claimed by the provider site where the consultant was located, while NWAU 40.16 was claimed by the provider site where the patient and support clinical staff were present. NWAU funding rates do not discriminate between new and review appointments, unlike the Queensland Weighted Activity Unit (QWAU) values, which were unavailable [15]. Failure to attend (FTA) rates were assumed to be the same across the 3 models. All prices are reported in Australian dollars (US \$0.62) and have not been converted to 2018 prices, as they represent the cumulative economic implications for a 3-year period.

Travel subsidy costs were calculated assuming that $17 \%$ of the non-FTA population for each financial year received subsidized
Patients travel from their home to receive in-person care at Townsville Hospital, which is the nearest hospital that provides orthopedic services.

Townsville Hospital pays for local staff as normal. Mount Isa Hospital pays to subsidize patient travel for individuals who claim from the Queensland Health Patient Travel Subsidy Scheme.

Townsville Hospital claims activitybased funding reimbursement for the appointment as the consultation provider.
Mount Isa Hospital directly employs a specialist to conduct videoconference consultations with patients located at Mount Isa Hospital. The specialist is located in a different geographical location from Mount Isa.

Mount Isa Hospital pays for all costs.

Mount Isa Hospital claims activitybased funding reimbursement for the appointment as the telehealth provider.

travel. Although the majority of patients are eligible to claim the travel subsidy, very few take advantage of the subsidy. The selection of 17\% was based on the 2016-2017 annual report from the North West HHS, in which Mount Isa Hospital is situated [16]. An average travel cost of A $\$ 1447$ per individual receiving the subsidy was assumed based on the 2016-2017 annual report, which stated that $\mathrm{A} \$ 14.48$ million was provided in patient travel subsidies to support 8623 patients. The travel amount was discounted by $2.5 \%$ per year for the two prior financial years, in accordance with local policies [16].

\section{Breakeven Point}

Using the calculations of cost per clinic, it is possible to calculate the breakeven point (ie, the minimum number of patients required per clinic to cover the cost of the service provision for that site). The breakeven point is the point at which the cost of running the outpateint clinic is negated by the income received from the appointments conducted. As FTA appointments do not yield income, they do not count toward the number of appointments required to break even.

\section{Sensitivity Analysis}

To investigate the uncertainty, we performed a sensitivity analysis. The income for each site was recalculated assuming $10 \%$ and $35 \%$ FTA rates. To investigate the effects of travel reimbursement, the population with subsidized travel was increased from $17 \%$ to a hypothetical $25 \%$. Additionally, using the base case figures, we calculated the number of appointments required for each clinic to break even and cover its costs.

\section{Results}

\section{Cost Analysis}

Given the costs for providing each model of service, a cumulative 3-year net benefit was calculated for each site (Table 
3). The analysis demonstrated that the only service model that resulted in a positive ROI for the rural site was the virtual health practitioner model of care.

The highest net benefit for the rural Mount Isa site was demonstrated for the virtual health practitioner model, followed by the telehealth model (Table 4). The benefits were higher compared to the patient travel model, where the site bears all the costs and does not generate any income. If patient travel reimbursement is increased from the assumed $17 \%$ of travel costs to $25 \%$, the travel costs for this single outpatient clinic are approximately $\mathrm{A} \$ 1$ million.

Table 3. Human resource costs associated with the 3 models of care at each clinic.

\begin{tabular}{|c|c|c|c|c|}
\hline Site and staff role & Hourly rate, A\$ & On-cost & Hours required per clinic & Cost, $\mathrm{A} \$$ \\
\hline \multicolumn{5}{|l|}{ Telehealth clinic } \\
\hline \multicolumn{5}{|l|}{ Princess Alexandra Hospital } \\
\hline Radiographer & 50.61 & 0.29 & 4 & 261.13 \\
\hline Administration (organization and clinic) & 34.88 & 0.29 & 2 & 89.99 \\
\hline Total & & & & 351.12 \\
\hline \multicolumn{5}{|l|}{ Mount Isa Hospital } \\
\hline Orthopedic specialist & 134.57 & 0.23 & 4 & 662.08 \\
\hline $\mathrm{RMO}^{\mathrm{a}}$ & 59.35 & 0.23 & 4 & 292.00 \\
\hline Nurse & 39.20 & 0.29 & 4 & 202.25 \\
\hline $\begin{array}{l}\text { Administration (organization and clinic) }+2 \text { hours paid to } \\
\text { Princess Alexandra Hospital }\end{array}$ & 34.88 & 0.29 & 10 & 449.96 \\
\hline Plaster technician & 28.73 & 0.29 & 4 & 148.23 \\
\hline Total & & & & 1754.52 \\
\hline \multicolumn{5}{|l|}{ Patient travel } \\
\hline \multicolumn{5}{|l|}{ Townsville Hospital } \\
\hline Orthopedic specialist & 134.57 & 0.23 & 4 & 662.08 \\
\hline Radiographer & 50.61 & 0.29 & 4 & 261.13 \\
\hline Administration (organization and clinic) & 34.88 & 0.29 & 6 & 269.98 \\
\hline Plaster technician & 28.73 & 0.29 & 4 & 148.23 \\
\hline Total & & & & 1341.42 \\
\hline \multicolumn{5}{|l|}{ Mount Isa Hospital } \\
\hline Travel subsidy for patients & $\mathrm{N} / \mathrm{A}^{\mathrm{b}}$ & N/A & Varied & Varied \\
\hline \multicolumn{5}{|l|}{ Virtual health practitioner } \\
\hline \multicolumn{5}{|l|}{ Mount Isa Hospital } \\
\hline Orthopedic specialist (off site) & 134.57 & 0.23 & 4 & 662.08 \\
\hline RMO & 59.35 & 0.23 & 4 & 292.00 \\
\hline Radiographer & 50.61 & 0.29 & 4 & 261.13 \\
\hline Nurse & 39.20 & 0.29 & 4 & 202.25 \\
\hline Administration (organization and clinic) & 34.88 & 0.29 & 8 & 359.97 \\
\hline Plaster technician & 28.73 & 0.29 & 4 & 148.23 \\
\hline Total & & & & 1925.66 \\
\hline
\end{tabular}

${ }^{\mathrm{a}} \mathrm{RMO}$ : resident medical officer.

${ }^{\mathrm{b}}$ Not applicable. 
Table 4. Three-year ROI analysis for the three service models. All values are given in Australian dollars.

\begin{tabular}{|c|c|c|c|c|c|c|c|c|c|}
\hline \multirow{2}{*}{$\begin{array}{l}\text { Clinic service model and } \\
\text { site }\end{array}$} & \multicolumn{2}{|l|}{$2014-15$} & \multicolumn{2}{|l|}{$2015-16$} & \multicolumn{2}{|l|}{$2016-17$} & \multicolumn{2}{|c|}{ Three-year total } & \multirow{2}{*}{$\begin{array}{l}\text { Three-year } \\
\text { net benefit } \\
\text { (profit) }\end{array}$} \\
\hline & Cost & $\begin{array}{l}\text { Income } \\
\left(\mathrm{FTA}^{\mathrm{a}}\right. \\
10 \%-35 \%)\end{array}$ & Cost & $\begin{array}{l}\text { Income } \\
\text { (FTA 10\%- } \\
35 \% \text { ) }\end{array}$ & Cost & $\begin{array}{l}\text { Income } \\
\text { (FTA 10\%- } \\
35 \% \text { ) }\end{array}$ & Cost & $\begin{array}{l}\text { Income } \\
\text { (FTA 10\%- } \\
35 \% \text { ) }\end{array}$ & \\
\hline \multicolumn{10}{|l|}{ Telehealth clinic } \\
\hline $\begin{array}{l}\text { Mount Isa Hospital } \\
\text { referral site }\end{array}$ & 50,507 & $\begin{array}{l}17,847 \\
(13,989- \\
19,369)\end{array}$ & 140,361 & $\begin{array}{l}153,693 \\
(134,986- \\
186,904)\end{array}$ & 143,870 & $\begin{array}{l}121,244 \\
(109,446- \\
151,540)\end{array}$ & 334,738 & $\begin{array}{l}292,785 \\
(258,421- \\
357,813)\end{array}$ & $-41,954$ \\
\hline $\begin{array}{l}\text { Princess Alexandra } \\
\text { Hospital provider site }\end{array}$ & 10,108 & $\begin{array}{l}67,547 \\
(52,589- \\
72,815)\end{array}$ & 28,090 & $\begin{array}{l}234,199 \\
(205,693- \\
284,806)\end{array}$ & 28,792 & $\begin{array}{l}184,082 \\
(166,169- \\
230,080)\end{array}$ & 66,990 & $\begin{array}{l}485,828 \\
(424,450- \\
587,701)\end{array}$ & 418,839 \\
\hline \multicolumn{10}{|l|}{ Patient travel } \\
\hline $\begin{array}{l}\text { Mount Isa Hospital } \\
\text { referral site }^{\mathrm{b}}\end{array}$ & $\begin{array}{l}-75,158 \\
(-110,526)\end{array}$ & $\mathrm{N} / \mathrm{A}^{\mathrm{c}}$ & $\begin{array}{l}-296,388 \\
(-425,234)\end{array}$ & N/A & $\begin{array}{l}-279,445 \\
(-391,146)\end{array}$ & N/A & $\begin{array}{l}-650,991 \\
(-926,906)\end{array}$ & N/A & $\begin{array}{l}-650,991 \\
(-926,906)\end{array}$ \\
\hline $\begin{array}{l}\text { Townsville Hospital } \\
\text { provider site }\end{array}$ & 39,580 & $\begin{array}{l}61,488 \\
(52,589- \\
72,815)\end{array}$ & 107,314 & $\begin{array}{l}240,503 \\
(205,693- \\
284,806)\end{array}$ & 109,996 & $\begin{array}{l}194,289 \\
(166,169- \\
230,080)\end{array}$ & 256,890 & $\begin{array}{l}496,281 \\
(424,450- \\
587,701)\end{array}$ & 239,390 \\
\hline \multicolumn{10}{|l|}{ Virtual health practitioner } \\
\hline $\begin{array}{l}\text { Mount Isa Hospital } \\
\text { referral site }\end{array}$ & 55,433 & $\begin{array}{l}67,547 \\
(52,589- \\
72,815)\end{array}$ & 154,053 & $\begin{array}{l}234,199 \\
(205,693- \\
284,806)\end{array}$ & 157,904 & $\begin{array}{l}184,082 \\
(166,169- \\
230,080)\end{array}$ & 367,390 & $\begin{array}{l}485,828 \\
(424,450- \\
587,701)\end{array}$ & 118,439 \\
\hline
\end{tabular}

${ }^{\mathrm{a}}$ FTA: failure to attend.

${ }^{\mathrm{b}}$ Costs for patient travel for this site are represented as cost (25\% patient travel paid).

${ }^{\mathrm{c}}$ Not applicable.

The analysis demonstrated that the only service model that resulted in a positive ROI for the rural site over the 3-year period was the virtual health practitioner model. The ROI for the rural site was $-100 \%$ for the patient travel model, from which they derived no income, $-12.5 \%$ for the telehealth model, and $32 \%$ for the virtual health practitioner model. Moreover, the ROIs for the metropolitan site were $93 \%$ for patient travel and $625 \%$ for telehealth; because the virtual health practitioner model is not applicable to the metropolitan site, it incurred neither cost nor income.

\section{Breakeven Point for Each Model of Care}

The breakeven analysis demonstrated the number of appointments that each site needs to conduct in order to cover the costs of providing the clinic service (Figure 1). For the travel model of care, the provider site must complete a minimum of 6 appointments to cover their costs; however, the rural site is unable to recoup their costs within this model due to the cost of travel and lack of income opportunity. Alternately, in the telehealth model of care, the provider site can break even by providing a minimum of 2 appointments, while the rural site must provide a minimum of 12 appointments. This disparity between the number of patients required to break even is due in part to the cost sharing arrangements for the service being modelled, where the rural site covers some human resource costs for the provider site (health practitioner and administration). 
Figure 1. The breakeven point for each model of care.

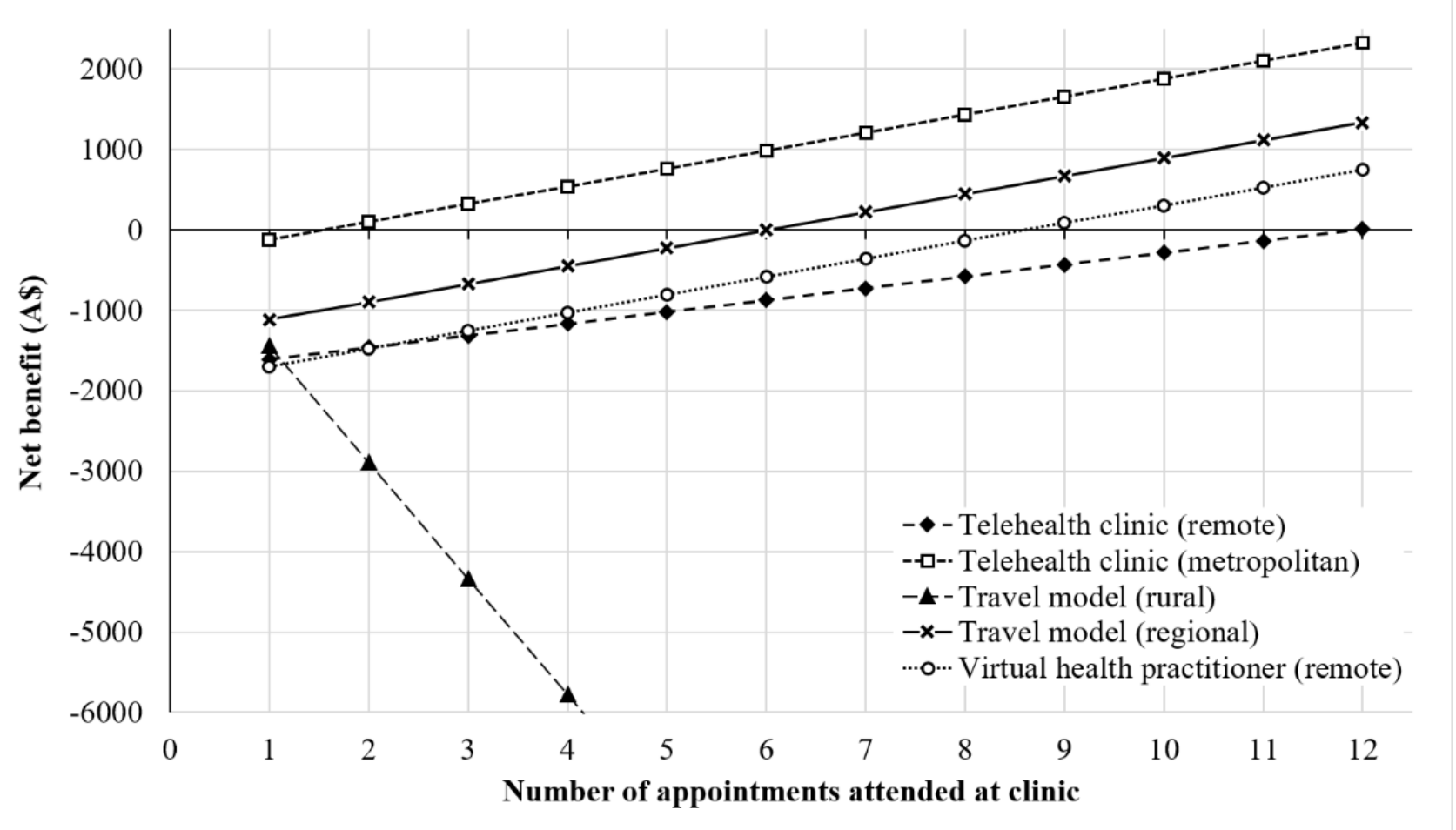

\section{Discussion}

\section{Principal Findings}

Our model demonstrated that rural health care providers can increase their ROI if they employ a virtual health practitioner as an alternative to subsidized patient travel or if they refer patients to telehealth clinics provided by a tertiary center. This largely results from savings from patient travel subsidies and generation of activity-based funding under the virtual health practitioner model. Increasing this to include all eligible patients $(100 \%)$ would increase the volume of negative ROI for the model (Figure 1) but would not change the results. Further, our modelling showed that the rural site could break even when 3 patients attended, rather than 12. Additionally, we demonstrated that rural sites receive greater net benefits from using a virtual health practitioner than from the other models of care. The greater the economic benefit that is achieved by the rural sites, the greater the benefit to the community in which they are located.

Previous studies have shown that in the context of the Australian health care system, rural sites and metropolitan sites can gain economic benefit from implementing a telehealth service model [2-4]. International studies have also demonstrated cost mimimization potential for videoconferencing in orthopedic applications [17,18] and high acceptance from rural health care practitioners and patients when specialists provide services using videoconferencing $[19,20]$. Our study adds to the body of knowledge on telehealth economics by modelling the use of virtual health practitioners; to the best of our knowledge, this has not been done previously.

In addition to economic advantages, the virtual health practitioner model may provide other benefits. Often, it is difficult to entice specialist clinicians to move to rural and remote areas to provide services $[2,6]$. The virtual health practitioner model provides an alternative by which rural and remote hospitals can gain specialty services for positions for which they are unable to recruit or retain staff or for positions that only require a small fraction of a full-time equivalent. One additional benefit is that patients can be referred back to primary care sooner, if appropriate, which will support the local rural health workforce.

\section{Implications for Practice}

While the economic focus in this paper is the optimization of outpatient clinics, the aim is not to advocate for a purely virtual care model for Australian patients. Instead, as models of care change to integrate telehealth and other virtual care provision modalities, we propose that alternate funding and employment models to those used in traditional in-person models of care (and telehealth emulations of these models) should be possible. Patients will still be required to travel for procedures, diagnostics, and outpatient appointments where a telehealth consultation is not appropriate.

Additional alternative models of care may present economic advantages; for example, a store-and-forward consultation with feedback to the general practitioner may be sufficient to diagnose and treat a simple fracture [21]. As telehealth services mature, patient cases can ideally be triaged to the most appropriate service model for their condition.

\section{Strengths and Limitations}

A strength of this study is the use of activity data from an existing telehealth service. By basing our analysis calculations on actual activity, we were able to present realistic economic examples for the 3 service models. 
A limitation of this study is that the economic analysis is based on a specific orthopedic clinic example; therefore, the findings lack generalizability. The ROI was estimated within the public funding models for the Australian state of Queensland (activity-based funding and travel subsidy scheme) and was based on local transportation costs. The model would require adaptation if it were transferred to alternate contexts.

The economic analysis presented here was for a service which experiences high and regular activity; the ROI estimates would need to be recalculated if the analysis were adapted for a service with low activity. As demonstrated by the example of this orthopedic fracture clinic, the virtual health practitioner model has a lower patient attendance rate requirement to break even on clinic costs. Additionally, the proportion of the population who claim the travel subsidy for this analysis was assumed to be $17 \%$. If this percentage was increased to reflect the near- $100 \%$ eligibilty of the population, it would only serve to reduce the already negative ROI for the small rural site; for this reason, a pragmatic assumption was made to reflect the real-world scenario.

The substitution rate of telehealth for in-person encounters is an additional variable that influences the ROI. The teleorthopedic service for the fracture clinic described in this paper is highly amenable to telehealth because physical examination of the patient is largely mitigated by the supplementary information provided by x-rays. When a physical examination is required, it can be performed by a junior doctor at the rural site. For other services, such as a general orthopedic clinic, it may not be possible to provide consultations by telehealth; as a result, the substitution rates will be lower. Different medical specialities have different telehealth substitution rates [22]. Hence, the economic findings of this study cannot be extended to all specialities. Economic modelling of blended models involving care delivered by a combination of telehealth, virtual health practitioners, outreach, and patient travel is an area for future research.

\section{Acknowledgments}

We would like to acknowledge Mr Andrew Murphy for his assistance with the logistical aspects of this study.

\section{Conflicts of Interest}

None declared.

\section{References}

1. Goodwin N. The State of Telehealth and Telecare in the UK: Prospects for Integrated Care. J Integr Care 2010 Nov 26;18(6):3-10. [doi: 10.5042/jic.2010.0646]

2. Moffatt JJ, Eley DS. The reported benefits of telehealth for rural Australians. Aust Health Rev 2010 Aug;34(3):276-281. [doi: 10.1071/AH09794] [Medline: 20797357]

3. Bradford NK, Caffery LJ, Smith AC. Telehealth services in rural and remote Australia: a systematic review of models of care and factors influencing success and sustainability. Rural Remote Health 2016;16(4):3808 [FREE Full text] [Medline: 27744708]

4. Wade VA, Karnon J, Elshaug AG, Hiller JE. A systematic review of economic analyses of telehealth services using real time video communication. BMC Health Serv Res 2010 Aug 10;19(4):283-286 [FREE Full text] [doi: 10.1186/1472-6963-10-233] [Medline: 20696073]

5. Merriman KK, Schmidt SM, Dunlap-Hinkler D. Profiling Virtual Employees. Journal of Leadership \& Organizational Studies 2016 Jul 21;14(1):6-15. [doi: 10.1177/1071791907304244]

6. Ramnath VR, Ho L, Maggio LA, Khazeni N. Centralized monitoring and virtual consultant models of tele-ICU care: a systematic review. Telemed J E Health 2014 Oct;20(10):936-961. [doi: 10.1089/tmj.2013.0352] [Medline: 25226571]

7. Humphreys J, Jones J, Jones M, Hugo G, Bamford E, Taylor D. A critical review of rural medical workforce retention in Australia. Aust Health Rev 2001;24(4):91-102. [doi: 10.1071/ah010091a] [Medline: 11842721]

8. McGill A, North J. An analysis of an ongoing trial of rural videoconference fracture clinics. J Telemed Telecare 2012 Dec;18(8):470-472. [doi: 10.1258/jtt.2012.gth110] [Medline: 23209275]

9. McGill A, North J. Teleconference fracture clinics: a trial for rural hospitals. ANZ J Surg 2012;82(1-2):2-3. [doi: 10.1111/j.1445-2197.2011.05952.x] [Medline: 22507484]

10. Annual Report 2017-2018. In: North West Hospital and Health Service Annual Reports. Mount Isa, Queensland: Queensland Health, Queensland Government; 2018.

11. Queensland Health. Patient Travel Subsidy Scheme (PTSS) guideline (part A) v1.3. In: Queensland Government Patient Travel Subsidy Scheme Information. Brisbane, Queensland: State of Queensland (Queensland Health); Aug $08,2016$.

12. Phillips JJ, editor. Measuring Return On Investment. Alexandria, Virginia, USA: American Society for Training And Development (ASTD); 1997.

13. Queensland Health Wage Rates. Queensland Health Human Resources Policies and Directives, Queensland Government. 2017. URL: https://www.health.qld.gov.au/hrpolicies/salary [accessed 2018-09-01]

14. Independent Hospital Pricing Authority (IHPA). 2018. National Pricing Model Technical Specifications 2018 URL: https:/ /www.ihpa.gov.au/what-we-do/pricing/national-pricing-model-technical-specifications [accessed 2018-09-01] 
15. Queensland Health: Health Funding Principles and Guidelines 2017-18.: Healthcare Purchasing and Funding Branch, Healthcare Purchasing and System Performance Division, Department of Health; 2018. URL: https://www.health.qld.gov.au/ system-governance/health-system/managing/funding-model [accessed 2018-09-01]

16. North West Hospital and Health Service Annual Reports.: Queensland Health, Queensland Government; 2017. Annual Report 2016-2017 URL: https://www.health.qld.gov.au/nwhhs/annual-reports [accessed 2018-09-01]

17. Harno K, Arajärvi E, Paavola T, Carlson C, Viikinkoski P. Clinical effectiveness and cost analysis of patient referral by videoconferencing in orthopaedics. J Telemed Telecare 2001;7(4):219-225. [doi: 10.1258/1357633011936435] [Medline: 11506757]

18. Ohinmaa A, Vuolio S, Haukipuro K, Winblad I. A cost-minimization analysis of orthopaedic consultations using videoconferencing in comparison with conventional consulting. J Telemed Telecare 2002;8(5):283-289. [doi: 10.1177/1357633X0200800507] [Medline: 12396857]

19. Haozous E, Doorenbos AZ, Demiris G, Eaton LH, Towle C, Kundu A, et al. Role of telehealth/videoconferencing in managing cancer pain in rural American Indian communities. Psychooncology 2012 Feb;21(2):219-223 [FREE Full text] [doi: 10.1002/pon.1887] [Medline: 22271543]

20. Sabesan S, Simcox K, Marr I. Medical oncology clinics through videoconferencing: an acceptable telehealth model for rural patients and health workers. Intern Med J 2012 Jul;42(7):780-785. [doi: 10.1111/j.1445-5994.2011.02537.x] [Medline: 21627743]

21. Caffery LJ, Taylor M, North JB, Smith AC. Tele-orthopaedics: A snapshot of services in Australia. J Telemed Telecare 2017 Dec;23(10):835-841. [doi: 10.1177/1357633X17732800] [Medline: 28950754]

22. Caffery LJ, Taylor M, Lucas K, Smith AC. Substitution rates of video consultations for traditional consultations at a tertiary public hospital. J Telemed Telecare 2016 Dec;22(8):453-458. [doi: 10.1177/1357633X16672767] [Medline: 27799447]

\title{
Abbreviations \\ FTA: failure to attend \\ NWAU: National Weighted Activity Unit \\ RMO: resident medical officer \\ ROI: return on investment
}

\author{
Edited by G Eysenbach; submitted 31.07.19; peer-reviewed by P Navarro, B Dinesen, B McKinstry; comments to author 11.09.19; \\ revised version received 01.10.19; accepted 23.03.20; published 21.05 .20 \\ Please cite as: \\ Snoswell CL, North JB, Caffery LJ \\ Economic Advantages of Telehealth and Virtual Health Practitioners: Return on Investment Analysis \\ JMIR Perioper Med 2020;3(1):e15688 \\ URL: http://periop.jmir.org/2020/1/e15688/ \\ doi: 10.2196/15688 \\ PMID: 33393922
}

(C) Centaine L Snoswell, John B North, Liam J Caffery. Originally published in JMIR Perioperative Medicine (http://periop.jmir.org), 21.05.2020. This is an open-access article distributed under the terms of the Creative Commons Attribution License (https://creativecommons.org/licenses/by/4.0/), which permits unrestricted use, distribution, and reproduction in any medium, provided the original work, first published in JMIR Perioperative Medicine, is properly cited. The complete bibliographic information, a link to the original publication on http://periop.jmir.org, as well as this copyright and license information must be included. 